\title{
CORONAVIRUS
}

\section{Consent during a pandemic}

Sir, on the advice of experts, the UK Government has chosen to control the pandemic by restricting individual rights and imposing radical measures limiting the freedoms of movement. Rapid legislation has enabled the state to control the circumstances under which individuals are permitted to meet or even leave their homes. ${ }^{1,2}$ These restrictions, which are unprecedented in peace time, have had a dramatic impact on the way people live their lives. Parliament and wider society have both accepted this temporary reduction in autonomy to preserve life. This is a utilitarian approach.

In a typical irreversible pulpitis situation, there is a choice of root canal treatment or extraction. As a responsible profession we have a duty to understand that the use of dental aerosols may compromise efforts to control the pandemic. Clinicians now face a new legal and ethical conundrum: to strictly preserve patient autonomy and give patients the treatment choices that current consent guidance obliges us to, or act in accordance with the aim of the government's pandemic response. Temporarily extending the utilitarian approach adopted by the government to dental treatment, especially where there is an effective alternative treatment, such as extraction, would be proportionate, reasonable, and assist the wider pandemic controls.

Current GDC guidance is silent on whether a clinician would be acting unlawfully should they to fail to offer aerosol generating procedures under the present COVID-19 pandemic. Whilst the option of root canal treatment for irreversible pulpitis may be a perfectly reasonable option in normal times, currently the dentist may consider that the increased risk of transmission of SARS-CoV-2 may be unacceptable to other people.

At this unique moment, the potential exists for a clinician to face charges of negligence and disciplinary proceedings for not adhering to GDC Standards. As the statutory dental regulator, the GDC has an obligation 'to protect, promote and maintain the health, safety and well-being of the public.'3 Accordingly, the GDC must show some decisive leadership by providing clarity, so that whilst acting in the nation's best interests, clinicians do not have to second guess the lawfulness/validity of the consent they obtain. Maintaining the status quo of expectations with regards to consent, with its basis in individual autonomy, would be contrary to the utilitarian approach adopted by the government.

R. Vasant, A. Haigh, London, UK

A spokesperson for the GDC responded: The guidance Messrs Vasant and Haigh are seeking is readily available on the GDC website and dental professionals have been emailed with updates throughout this crisis.

On 18 March we published a statement (https://bit.ly/2LUTXvc) which made clear that: Where the risk of infection - from patient to practice staff or the other way round - is greater than the risk to the patient of not providing treatment, it will be in everybody's interest not to go ahead. That is increasingly likely to mean that there are some patients who should not be treated and some treatments which should not be offered in a general practice environment, to protect the safety of the dental team and of other patients. Where those lines are best drawn at any given time will again be for the health authorities of each nation to decide, for our part we can say very clearly that we will respect professional judgements made on that basis.
That followed a statement made by the UK's healthcare regulators, including the GDC (https://bit.ly/2WV3598), on 3 March, which said that: We recognise that in highly challenging circumstances, professionals may need to depart from established procedures in order to care for patients and people using health and social care services. And went on to say that: We recognise that the individuals on our registers may feel anxious about how context is taken into account when concerns are raised about their decisions and actions in very challenging circumstances. Where a concern is raised about a registered professional, it will always be considered on the specific facts of the case, taking into account the factors relevant to the environment in which the professional is working. We would also take account of any relevant information about resource, guidelines or protocols in place at the time.

Our COVID-19 hub is available online (https://bit.ly/3c0FuZ4) for further advice and information from the GDC, and signposting to that from other relevant organisations.

\section{References}

1. Coronavirus Act 2020. Available at: http://www. legislation.gov.uk/ukpga/2020/7/contents/enacted (accessed May 2020).

2. The Health Protection (Coronavirus) Regulations 2020. Available at: http://www.legislation.gov.uk/ uksi/2020/129/contents/made (accessed 23 May 2020).

3. Dentists Act 1984. Available at: http://www.legislation. gov.uk/ukpga/1984/24/contents (accessed 23 May 2020).

https://doi.org/10.1038/s41415-020-1711-7

\section{Knocked out!}

Sir, during the pandemic we have found an increasing number of paediatric patients referred by $\mathrm{A} \& \mathrm{E}$ at St George's Hospital with dento-alveolar injuries, specifically avulsion. Patients have been referred via the Acute Emergency Dental Service to the Paediatric 
Department for a dental trauma review following splinting of avulsed teeth. The increasing number of dento-alveolar injuries during lockdown might be due to children spending more hours at home playing than they normally would.

Parents attending the Paediatric

Department for a follow-up have complained about the lack of information available to them on managing avulsion injury.

Such a lack of easily accessible information directly impacts the prognosis of the tooth and has a significant impact on the quality of life of the child with potential cost and time required for treatment. Improvement in the delivery of services and provision for better information for the public should be a priority during the COVID-19 pandemic where access to dental care is very limited.

K. Zaheer, London, UK https://doi.org/10.1038/s41415-020-1721-5

\section{Hydroxychloroquine shortage}

Sir, readers will be aware of the autoimmune disease systemic lupus erythematosus (SLE), owing to the associated oral, head and neck manifestations. The efficacy of hydroxychloroquine in reducing the risk of severe lupus flares is well documented.

Given that the emergence of a suitable vaccine against the 2019 coronavirus disease (COVID-19) may be a seemingly distant prospect, several clinical trials are underway to evaluate a potential role for existing drugs. Hydroxychloroquine is one such drug with hypothesised mechanisms of action and in vitro evidence supporting the inhibition of severe acute respiratory syndrome coronavirus $2 .{ }^{1}$

However, in an almost desperate attempt to lessen the burden of the pandemic, physicians are sporadically prescribing the drug with little evidence informing whether they are appropriate for treating COVID-19. Propagated in part by President Trump's endorsement, the sudden demand for hydroxychloroquine has created a shortage in its availability to patients requiring this medication. ${ }^{3}$ The impact of withdrawing the medication for just a fortnight can exacerbate flares and heighten disease activity in otherwise stable SLE patients. The drug is vital and unique in its ability to prevent further systemic complications and increase chance of survival. ${ }^{5}$

The attention drawn to the COVID-19 pandemic risks compromising the provision of care to those with chronic conditions. The case for patients with SLE could represent one of many interruptions to treatment. Evaluating the severity of each compromise is essential. The decision to champion hydroxychloroquine so hastily raises yet more questions on the decisionmaking approaches, which currently show considerable disparity. Several recent clinical studies have investigated hydroxychloroquine for COVID-19 patients but these have been at high risk of bias, hence the need for large randomised placebo-controlled clinical trials to determine the potential benefits and harms before any role can be recommended. This story highlights the importance of an evidence-based approach that we increasingly recognise in the practice of dentistry.

\section{J. Patel, Leeds, P. Coulthard, London, UK}

\section{References}

1. Yao X, Ye F, Zhang M et al. In vitro antiviral activity and projection of optimized dosing design of hydroxychloroquine for the treatment of Severe Acute Respiratory Syndrome Coronavirus 2 (SARS-CoV-2). Clin Infect Dis 2020; DOI: 10.1093/cid/ciaa237.

2. Lenzer J. Covid-19: US gives emergency approval to hydroxychloroquine despite lack of evidence. BMJ 2020; 369: $\mathrm{m} 1335$.

3. Jaffe S. Regulators split on antimalarials for COVID-19. Lancet 2020; 395: 1179.

4. Canadian Hydroxychloroquine Study Group. A randomized study of the effect of withdrawing hydroxychloroquine sulfate in systemic lupus erythematosus. N Eng/ J Med 1991; 324: 150-154.

5. Alarcón G, McGwin G, Bertoli A et al. Effect of hydroxychloroquine on the survival of patients with systemic lupus erythematosus: data from LUMINA, a multiethnic US cohort (LUMINA L). Ann Rheum Dis 2007; 66: 1168-1172.

https://doi.org/10.1038/s41415-020-1722-4

\section{Age-appropriate antibiotics}

Sir, antimicrobial stewardship is as important now as before the pandemic and this includes ensuring correct doses are prescribed. Treating paediatric patients in an Urgent Dental Care Centre at Newcastle Dental Hospital, we have worryingly seen a shocking proportion of children who have been prescribed age-inappropriate, suboptimal doses of antibiotics and subsequently referred for treatment as 'unresponsive to antibiotics'. It is perhaps unsurprising to note a lack of clinical improvement in these cases. Paediatric doses for amoxicillin increased in 2014 and excellent guidance on antibiotic prescribing is available from multiple organisations such as FGDP ${ }^{1}$ and SDCEP. ${ }^{2}$ We simply wish to highlight that any child over five years of age should be prescribed an 'adult' $500 \mathrm{mg}$ dose of amoxicillin. This crucial change in practice will improve patient safety and management not only during this coronavirus crisis, but also to reduce the long-term potential for antimicrobial resistance for future generations.

O. Sumner, S. Datta, Newcastle upon Tyne, UK

\section{References}

1. Faculty of General Dental Practice. Antimicrobial prescribing for general dental practitioners. 2nd Edition. 2016.

2. Scottish Dental Clinical Effectiveness Programme. Drug prescribing for dentistry. 3rd edition 2016, updated 2017. https://doi.org/10.1038/s41415-020-1723-3

\section{Repurposing the 7Ps}

Sir, as a British Army Dental Officer I was taught the 7Ps: Prior Planning and Preparation Prevents Piss Poor Performance. Being more polite, the United States Air Force changed the fifth $\mathrm{P}$ to 'pitifully.' This is a shame as the surprise and fun of the mild expletive makes the adage memorable. Later versions sometimes substituted 'practice' for the third P.

We were also taught to be 'joined up. The Faculty of General Dental Practice (FGDP) produced a comprehensive list of guidance, news and resources for general dental practice in the COVID-19 era. ${ }^{2}$ Not surprisingly, there are inconsistencies and differing viewpoints, both within dentistry and with our medical and nursing colleagues about the new normal, particularly concerning aerosol generating procedures (AGPs). These are critical to modern dentistry, but are not unique to us.

It has been noted anaesthetists consider working in the upper airway to be an AGP but dentistry is not mentioned. ${ }^{3}$ The latest Cochrane commentary on personal protective equipment (PPE) for general dental practice states 'none of the 24 identified studies... was based in the dental environment or included members of the dental team.' ${ }^{4}$ The Centre for Evidence Based Medicine's commentary on PPE in primary care concerns general medical practice. It introduces a new term of aerosol generating exposures (AGE) to include AGPs and additional risks like patients coughing. Also, requiring gold plated evidence may be the enemy of good policy. We need to look at all evidence, both observational and experimental. ${ }^{5}$

Following the Severe Acute Respiratory Syndrome (SARS) outbreak 2002-2004, PPE for dental procedures was proposed. ${ }^{6}$ It did not discuss wider implications, such as 